\title{
BMJ Open Leadership and management in the undergraduate medical curriculum: a qualitative study of students' attitudes and opinions at one UK medical school
}

\author{
Thelma Quince, ${ }^{1}$ Mark Abbas, ${ }^{2}$ Sughashini Murugesu, ${ }^{3}$ Francesca Crawley, ${ }^{4}$ \\ Sarah Hyde, ${ }^{5}$ Diana Wood, ${ }^{6}$ John Benson ${ }^{7}$
}

To cite: Quince T, Abbas M, Murugesu S, et al.

Leadership and management in the undergraduate medical curriculum: a qualitative study of students' attitudes and opinions at one UK medical school. BMJ Open 2014;4:e005353.

doi:10.1136/bmjopen-2014005353

- Prepublication history and additional material is available. To view please visit the journal (http://dx.doi.org/ 10.1136/bmjopen-2014005353).

Received 27 March 2014 Revised 9 June 2014 Accepted 11 June 2014

CrossMark

For numbered affiliations see end of article.

Correspondence to Dr Thelma Quince; taq100@medschl.cam.ac.uk

\section{ABSTRACT}

Objective: To explore undergraduate medical students' attitudes towards and opinions about leadership and management education.

Design: Between 2009 and 2012 we conducted a qualitative study comprising five focus group discussions, each devoted to one of the five domains in the Medical Leadership Competency Framework, (Personal Qualities, Working with Others, Managing Services, Improving Services and Setting Direction). Each discussion examined what should be learnt, when should learning occur, what methods should be used, how should learning be assessed, what are the barriers to such education.

Participants: 28 students from all three clinical years (4-6) of whom 10 were women.

Results: 2 inter-related themes emerged: understanding the broad perspective of patients and other stakeholders involved in healthcare provision and the need to make leadership and management education relevant in the clinical context. Topics suggested by students included structure of the National Health Service (NHS), team working skills, decision-making and negotiating skills. Patient safety was seen as particularly important. Students preferred experiential learning, with placements seen as providing teaching opportunities. Structured observation, reflection, critical appraisal and analysis of mistakes at all levels were mentioned as existing opportunities for integrating leadership and management education. Students' views about assessment and timing of such education were mixed. Student feedback figured prominently as a method of delivery and a means of assessment, while attitudes of medical professionals, students and of society in general were seen as barriers.

Conclusions: Medical students may be more open to leadership and management education than thought hitherto. These findings offer insights into how students view possible developments in leadership and management education and stress the importance of developing broad perspectives and clinical relevance in this context.

\section{Strengths and limitations of this study}

Focus groups permitted students to direct the flow and content of the discussion, enabling them to delve deeper into their views about leadership and management education.

- The trustworthiness of the data was enhanced by the use of multiple coders.

- The research team is not aware of any other qualitative study addressing this topic with the UK undergraduate medical students.

- It was conducted in one UK medical school. Although drawn from all three clinical years the number of participating students was small and inevitably self-selecting.

\section{INTRODUCTION}

Leadership and management skills are required to ensure provision of high-quality patient care. ${ }^{1-5}$ Active engagement of clinicians in leadership and management appears beneficial and positive associations have been found between doctors appointed to hospital boards of directors and clinical outcomes and overall performance. ${ }^{6-10}$ Clinical quality depends on interprofessional team working hence leadership and management skills are needed at all levels. ${ }^{11}{ }^{12}$ Recently the UK NHS Institute for Innovation and Improvement and Academy of Medical Royal Colleges developed the Medical Leadership Competency Framework (MLCF) outlining the competencies expected of practicing clinicians. ${ }^{13}$

Leadership and management abilities are recognised as key areas in postgraduate medical education. ${ }^{14}$ In the UK demonstration of competency in the MLCF's domains is fundamental for career progression and necessary for satisfactory completion of the 


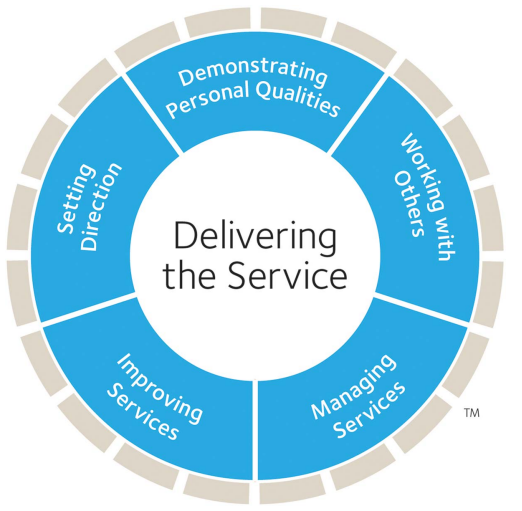

Figure 1 The Medical Leadership Competency Framework (NHS (National Health Service) Institute for Innovation and Improvement).

Annual Review of Competence Progression (ARCP) required for gaining accreditation. However, to be effective, engagement needs to start earlier in medical training. ${ }^{15-17}$

Medical schools are charged with the responsibility of training physicians to be diagnosticians and to understand resource management, financial considerations and multiprofessional team working. ${ }^{18}$ Despite this, and the publication in 2010 of guidance for undergraduate medical education relating to the MLCF, (publication was after the start of this study and included three authors of this paper as contributors), education in leadership and management is less well developed at the undergraduate level and there is limited literature on how to incorporate this into the undergraduate curriculum. ${ }^{19-21}$

We conducted a qualitative study exploring medical students' attitudes towards and opinions about leadership and management education in the undergraduate curriculum .We asked the following questions:

- What leadership and management content should be addressed?

- At what point in the undergraduate curriculum should the teaching and learning occur?

- What methods should be used?

- How should learning be assessed?

- What are the barriers to such education?

\section{METHODS}

We adopted a qualitative approach using focus group discussions to explore issues relevant to students and to generate acceptable, practical suggestions. An essentialist thematic analysis was used, focusing on the ideas, experiences, opinions and meanings presented by the participants. ${ }^{22}$

The standard medical course in Cambridge comprises three core science years, with a small element of clinical experience, followed by three clinical years, each comprising approximately 140 students. Between 2009 and 2012 clinical students from each of the years 4-6 were invited by email to participate in the study. Two reminders were issued 2 weeks apart and those willing to participate were contacted. Five focus group discussions were held, one relating to each dimension of the MLCF (figure 1).

Participants received an outline of the MLCF's competencies for medical students for the dimension under consideration together with a topic guide. ${ }^{19}$ This information was briefly repeated at the outset of the discussions.

Written consent to participate was requested in the initial email and again, at the outset of each discussion. Discussions lasted between 90 and $120 \mathrm{~min}$ and, with participants' permission, were recorded and transcribed verbatim. Transcribed data were anonymised and entered into NVivo V.9 software (QSR International Pty Ltd, Melbourne, Australia).

In total 28 clinical students took part (10 women). The nature of participants and schedule of discussions are given in table 1 . All year 6 participants had received formal instruction in leadership and management comprising a 1-day course, midway in their final year.

Using the 'Setting Direction' discussion TQ and SM independently derived coding frameworks. Subsequent discussions generated a common framework which TQ extended to the other transcripts. JB and FC independently considered the appropriateness of the resulting framework to all dimensions and adjustments were made. TQ JB and FC independently applied the agreed framework to a selection of transcribed data. A high level of agreement of code application was found $(>90 \%)$. Following discussion between TQ JB and FC an

Table 1 Focus participants and schedule of discussions

\begin{tabular}{llll}
\hline Dimension & Number of students & Date of focus group discussion & Facilitator(s) \\
\hline Working with Others & $6(2$ women $)$ & July 2009 & $\mathrm{MA}, \mathrm{TQ}$ \\
Personal qualities & $7(3$ women $)$ & October 2009 & $\mathrm{MA}$ \\
Managing services & $4(1$ woman) & October 2010 & $\mathrm{MA}$ \\
Improving services & $4(2$ women) & October 2011 & $\mathrm{MA}$ \\
Setting direction & $7(2$ women $)$ & October 2012 & $\mathrm{TQ}, \mathrm{SM}$ \\
Total & $28(10$ women) & & \\
Stage of course & Year 4 & Year 5 & Year 6 \\
Number of students & 7 & 9 & 12 \\
\hline
\end{tabular}


Box 1 Broad categories of codes (detailed codes given in online supplementary appendix 1)

1. Awareness: Recognition of the need to understand leadership and management in general, its relevance to future work and the levels at which it applies.

2. Timing and structure: When in the undergraduate curriculum should teaching about leadership and management start and how should or could that be structured?

3. Methods of delivery. How should leadership and management teaching be delivered and the advantages and disadvantages of different methods.

4. Assessment. How should the leadership and management learning be assessed and the advantages and disadvantages of different methods of assessment.

5. What should be taught? What topics should be covered in leadership and management teaching in the undergraduate curriculum?

6. Barriers: Factors that may inhibit undergraduate medical students' interest in and learning about leadership and management.

overall coding framework was agreed (box 1) and applied by $\mathrm{TQ}$ to all transcribed material.

Coded data were scrutinised and emerging themes initially identified by $\mathrm{TQ}$ using an inductive semantic approach. These were based on the extent to which the theme captured something important to the overall research questions and the extent to which the theme accurately reflected the entire data set rather than one dimension alone. ${ }^{23}$ Themes were considered against the transcribed and coded data independently by JB, FC and $\mathrm{SH}$, and following discussion, the final analytic structure agreed. Students participating in the 'Setting Direction' discussion were able to comment on the results of their discussion which were presented as a poster.

This paper reports generic results, potentially relevant to other medical schools. Opinions and recommendations specific to the Cambridge Medical Course are not presented.

\section{RESULTS}

Two strongly inter-related themes were identified: understanding the broad perspective of patients and other stakeholders involved in healthcare provision and the need to make leadership and management education relevant in the clinical context (figure 2). The resulting students' suggestions and opinions are presented in relation to each theme and in a third section relating to both themes.

\section{Understanding perspectives (Section 1)}

Students believed that leadership and management education should encourage them to understand perspectives at three levels:

- Society as a whole;

- Organisations in which they would work;

- Individuals with whom they would interact.

These considerations influenced students' suggested topics for incorporation into the undergraduate curriculum (figure 3).

\section{Societal perspectives}

The economic, political and social context within which UK healthcare operates was appreciated. Clinical judgement and resource allocation were seen as linked and hence the need for tomorrow's doctors to become more involved and engaged in leadership and management.

External circumstances directly affect how we deliver care healthcare...that makes the idea of resource allocation and clinical judgement and the managerial aspect to that, perhaps more relevant for us now than for doctors previously...but I don't think it is something that has quite filtered down to medical students. F3

\section{Organisational perspectives}

All participating students had undertaken placements in hospitals and general practice. Students recognised the organisational context of healthcare and the need to

Figure 2 Relationships between

Themes themes and codes.

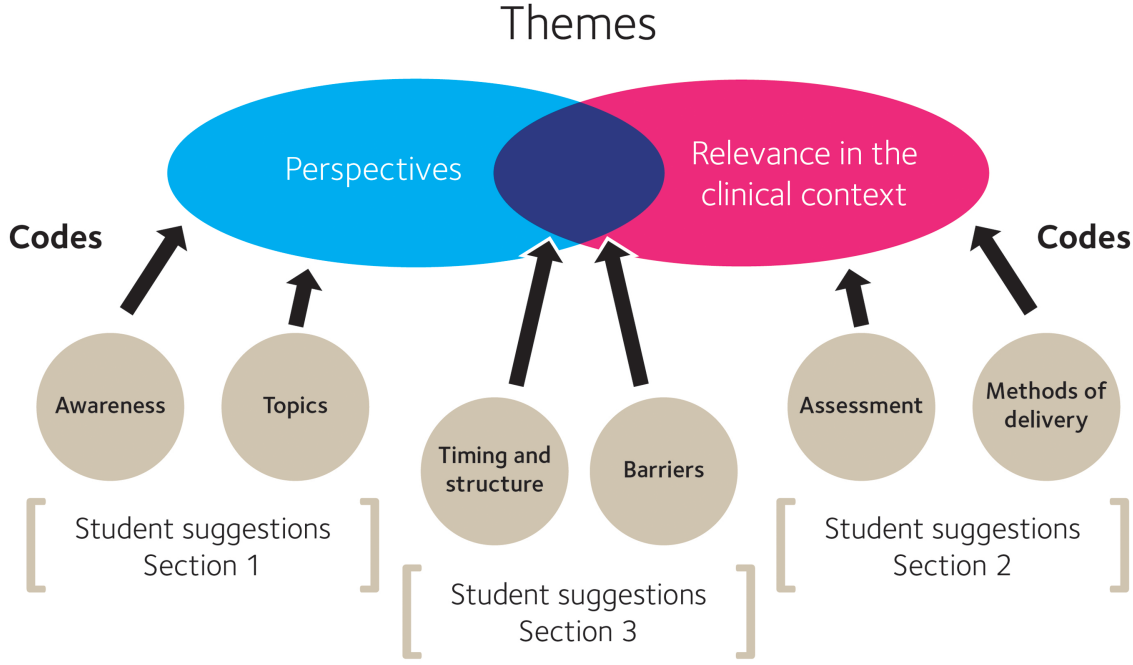




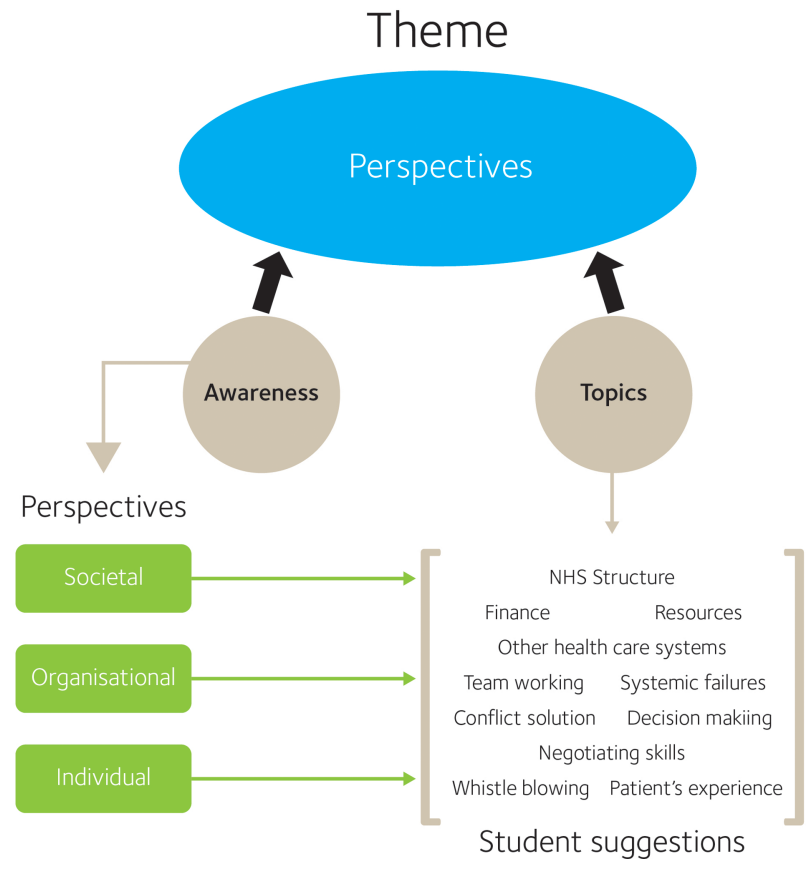

Figure 3 Perspectives: relationships between codes and student suggestions.

take account of the perspectives of managers, other healthcare professionals and patients.

In the hospital, there were no beds so all medical elective admissions have been cancelled...consultants were told this morning...I presume by a manager-do your estimated daily discharge and try and discharge patients...So that's not necessarily offering the best care you can-the consultants may fight for it but at the end of the day there is a whole queues of patients lining up to come into the hospital and we've got limited resources. M17

There was awareness of the role of teams, potential conflicts within teams and between clinicians and managers and, more importantly, the influence of management and leadership skills on team performance and thereby patient care.

I have seen some teams that work really well together and deliver excellent patient care... and then some teams have such problems between doctors and nurses. F2

Ability to manage teams was seen as part of the doctor's job and hence the need to develop this skill at the undergraduate level was identified. Students lacking such education reported feeling unable to evaluate or learn from the team dynamics they observed in clinical practice.

We don't necessarily have an organised framework in our heads to articulate to ourselves what kind of organisational culture this is and to therefore to understand what we need to take from it and...what is worth practicing ourselves. M3
Individual perspectives

Involving the patient in his/her care and clinicians acting as advocates for that care were seen as important, as were patients' diverse and individual needs. Poor and exemplary doctor/patient relationships and their potential educational impact were reported frequently.

Pressures faced by individual doctors in all aspects of their daily practice were acknowledged. Some students were surprised that their own performance as doctors would be assessed and they would also be expected to assess that of their colleagues.

I think the managing performance bit is something that struck me because you see it on the wards when you see junior Drs filling out surveys and questionnaires on their colleagues and saying how's their performance and things. I was quite taken a back as I didn't know that it was that formal and structured, it's probably a good thing...I think...making us aware that you will have to judge our colleagues would be quite useful. M3

\section{Suggested topics for inclusion in the undergraduate curriculum}

Topics relating to the societal perspective included the structure of the National Health Service (NHS), including financial and resource constraints. Some students felt that comparisons with developments in healthcare systems in other countries should be included.

Students' clinical experience fostered awareness of the complicated nature of clinical coding and its financial implications and there was a need to understand some of this, even at the undergraduate level.

You are leading or being part of a team to maximise efficiency so whatever you do there's an opportunity cost so you can bring some management economics kind of into that...to make an informed decision also you have to think of the human aspects of medicine so it is very much like a risk benefit sort of thing. That notion has to be put across slightly better in the medical curriculum. M9

Effective communication was seen to improve team working. However, this was not always applied to team work and extending communication-skill teaching to include this was suggested. Greater interaction with manager and learning to involve, accept and value were also seen to foster effective team work.

Negotiating, conflict resolution skills, decision-making and evaluating change were proposed for inclusion. Students who had experience of management studies highlighted this.

They had something called the negotiation workshop where you learnt how to talk to, convince other people, and how to put your points across...I think that would be really helpful for doctors and as we go on to interact with other professions as well. F9

And no way along the process, in my mind in medicine, is it defined as to how to make a decision. M15 
Understanding patients' experience of their journey through the healthcare system and how they might be enabled to take part in decision-making in respect of that care was considered relevant. Participants appeared unsure of their position as medical students when confronting patient safety issues and the routes for progressing problems. As a result patient safety and whistleblowing were suggested frequently as topics for inclusion.

Audit was seen as a specific topic for inclusion in leadership and management education, as well as a method by which organisational aspects could be taught.

\section{Relevance in the clinical context (Section 2)}

The view that leadership and management education should be relevant for, and relate closely to, the clinical context was strongly expressed. Relevance was seen to foster greater awareness of the social, economic and political context within which healthcare operated. In turn relevance influenced students' views about methods of delivery, assessment and feedback on their performance (figure 4).

You need to use examples...real life examples of hospitals that are failing or management teams that have failed and try and look at why they failed, cause it kind of brings it to attention that this kind of thing does happen and the fact that people die because of it. M18
Methods of delivery

Experiential methods were preferred with many opportunities for using clinical experience given as examples. These include preset questions, observation and reflection, critical appraisal, greater involvement in ward activities and learning from mistakes.

Take an event that has happened in the clinical area that you are working in at the minute, and try to go back over it and think why did this event happen? What were the risks that were involved and then make a discussion about how you could improve them afterwards. F1

Reflecting on observations was regarded generally as a continual process but views were divided as to how to incorporate this into leadership and management learning. Some students supported reflective essays. Others felt such exercises often became formulaic, preferring one-to-one or small group discussions.

Greater involvement in wards was seen to facilitate learning and audits as an extension to this. However, leadership and management aspects needed to be clearly highlighted otherwise audits could become mere paper exercises. A great deal of informal teaching of leadership and management was seen on clinical attachments which could be formalised and incorporated within the existing curriculum. Critical appraisal of how consultants and others demonstrated leadership and
Figure 4 Relevance in the clinical context: relationships between codes and student suggestions.

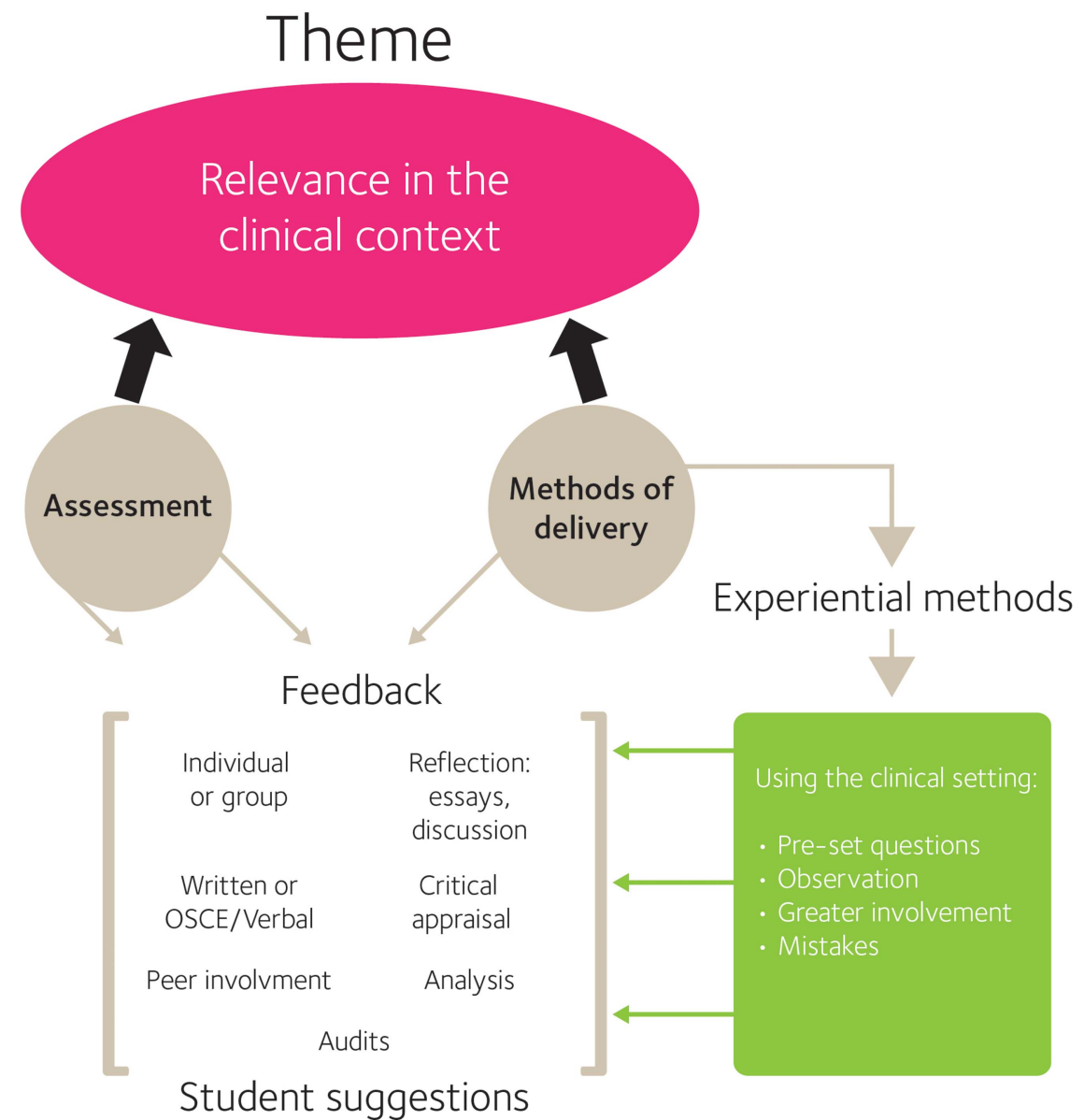


management skills was suggested as a way of identifying such skills in the clinical context.

We don't really need an extensive course as a lot of the skills are already there, it's just as we talked about there are different ways of getting people to think about themselves in a different way. All the skills about the patient we learnt in (communication skills teaching)- actually, we need to think about them in the context of leadership and teamwork, and how I should relate to my colleagues, the people I work for, the people I work with and the people that work for me. M12

Leadership and management topics could also be taught by analysing and reflecting on actual mistakes at all levels, but concerns were raised about whether the information generated could be handled, particularly if it raised whistleblowing issues. One focus group took place during the publicity surrounding the Francis Report on the failures at Mid Staffs NHS Foundation Trust. ${ }^{3}$ Students in this group commented on how uninformed they were about systemic failures on this scale.

While endorsing case-based or problem-based learning as a method of delivery, the leadership and management aspects had to be made explicit.

I think the structure where you go through the scenario and understand why it is important...but teaching on leadership and management would be quite alien to medical students as we haven't experienced this before. I think...to make the relevance quite apparent is really important. M3

Team-building and coding exercises were reported as beneficial for leadership and management education by those students who had undertaken them. Very few students mentioned 'role play' as a useful method.

There was little support for didactic teaching methods. A few students argued that some topics could be introduced through lectures, if the material was clinically relevant, drew on practical experience and presented enthusiastically. Others saw lectures as inappropriate.

\section{Assessment}

Views about assessment were divided and its value questioned. Supporting assessment were views that without assessment there would be no measurable outcomes to evaluate learning and learning would not be seen as important. Contrasting views were that assessment would reduce interest and constitute yet another 'hoop' through which students needed 'to jump'. Similarly contentious was the issue of whether there should be minimum standards that medical students had to achieve.

There should be some kind of defined minimum standard you should have for certain skills and that basically the same with clinical skills for example with OSCEs you repeat the assessment until you pass. F7

I disagree with you totally. M11
There was also no consensus as to whether assessment should be at the group or individual level. Some felt that assessment through a group task or presentation would be less threatening. Suggested group tasks included casebased or problem-based exercises using structured scenarios or real examples of failing wards, audits, root-cause analysis exercises and role-play team-work exercises. Directly observing group performance was also suggested. These would need clear and detailed assessment criteria extending beyond simple 'pass and fail' and assessment undertaken by experienced personnel. Others felt that peers should be involved in assessment.

There could be a group task so four or five applicants are given a task and there would be like 2 assessors looking at the interaction of the people. M7

I think it would be good idea if it was peer assessed as well because you know part of the whole leadership thing surely that is about being able to take positive criticism from the team that you are working in to incorporate their ideas so perhaps it would be good in a way. F1

Similar suggestions about observing individual student's leadership and management performance were also made. Other suggestions included written short reports of observed scenarios or specific real practice, critical appraisal exercises, OSCE-type exercises, other verbal assessments through viva-type situations. One interesting suggestion was that assessment should cover what had been observed and the analysis of that observation in terms of leadership and management performance.

Demonstrated that you are aware of how to make a decision, you are aware of the problems in the scenario if there was one and you know some techniques of how to improve it or if not then who to refer to or who to speak to. M15

\section{Feedback}

Feedback figured strongly as a method of delivery and a method of assessment. Students indicated that feedback was frequently asymmetrical: they were asked to give feedback but often did not receive feedback or received feedback of limited value in terms of learning. For some, this was discouraging. Views about feedback directly from patients and from peers were divided. Some students felt that feedback from patients facilitated understanding of their perspectives, others saw its value in the leadership and management context as limited. Similarly contentious was feedback from peers: some participants felt it would be questioned and not regarded seriously, others saw it as a precursor to $360^{\circ}$ appraisal useful in encouraging team working.

Using the 360 thing as an example you realise that your colleagues, it encourages working well in a team and the importance of it and if you are working well with you colleague you are going to get OK feedback but if you just regard your colleagues within the team, ok they are not 
as good as me, they're not pulling their weight. It encourages teamwork I would say. M5

It was also felt that feedback could greatly enhance the learning effectiveness of reflection, and exercises such as audits.

In terms of the assessment of the course, if you are going to have things then it is much better, especially in something like audit or management where it is a continual process, it is not something that you do and then you forget about, you should get feedback about things and it is not just a pass/fail something like that. F2

\section{Understanding perspectives in their clinical context and relevance (Section 3)}

Students' views about timing and structure and of leadership and management education in the undergraduate curriculum, together with what they considered to be the barriers to such education were shaped by both themes (figure 5).

\section{When should leadership and management education take place?}

Conflicting views were expressed about when undergraduate students should be made aware of the economic, political and social context of healthcare provision. Some students felt that awareness needed to start at the undergraduate level in order to avoid potential 'resentment' when confronted with management tasks as practicing clinicians. Others felt that awareness could potentially disillusion medical students. 'Consumerist' attitudes and demands expressed by some patients were seen as possible sources of conflict and

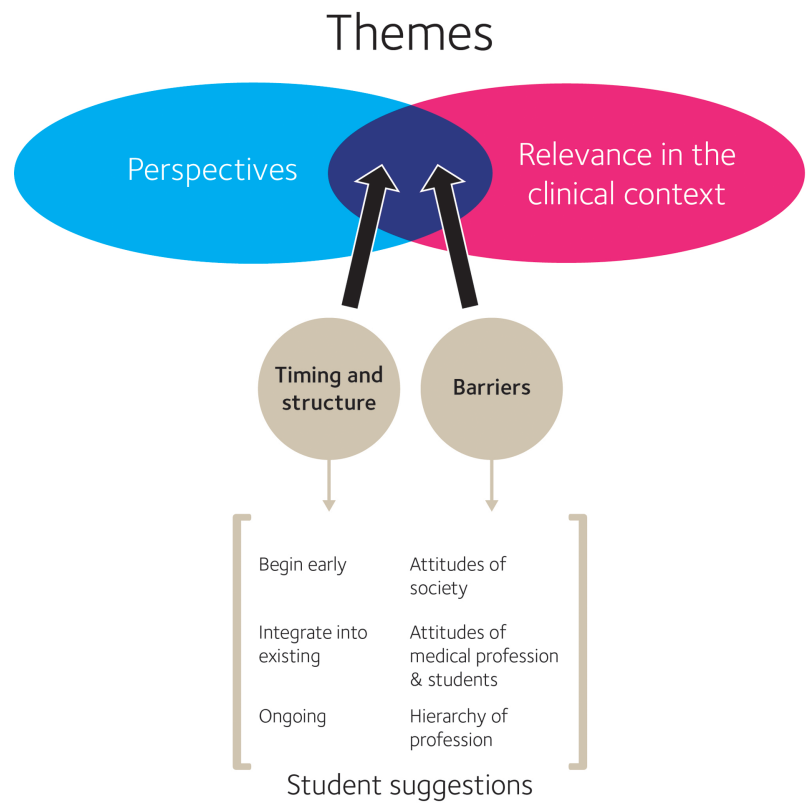

Figure 5 Perspectives and relevance in the clinical context: relationships between codes and student suggestions. hence likely to inhibit medical students' appreciation of the role of leadership and management.

Even as an F1 Dr doing paperwork, making minor management decisions are an inevitable part of junior doctor life...So I think it important that students are made aware...in order to remove the resentment. M4

However, there was support for the notion that developing organisational perspectives to healthcare provision should begin early. It was generally felt that to appreciate fully the importance of leadership and management to patient care, students had to have experienced the clinical context, but opinions were divided as to when to introduce some of the suggested topics, and in particular the issue of whistleblowing. The overriding view was that leadership and management education should be incorporated into the existing curriculum and hence be ongoing.

\section{The barriers to leadership and management education}

Changing attitudes within society and the medical profession itself were seen as potential barriers necessitating greater leadership and management education.

From an organisational perspective, the hierarchical nature of the medical profession and medical students' attitudes towards this hierarchy were cited as potential barriers. The existing career structure was seen not to facilitate or encourage the practice and exercise of management skills. This view of hierarchy underscored students' views of the complexities of whistleblowing.

I think that if the GMC wants to encourage people to have great management skills, imagination and situational awareness then they need to empower people to be able to use those things and make us feel a little bit less constrained as medical students climbing up the very narrow career ladder. F7

Attitudes towards leadership and management education held by existing clinicians and medical students were seen as potential inhibitors. Similarly some consultants were seen as holding negative attitudes to teaching students in general. Developing awareness of the potential beneficial impact of management decisions on the patient was seen as negating such attitudes.

\begin{abstract}
These consultants are the consultants with a clinical background already you know..."in my day when I was a lad you know". Is it that or is it actually they feel we are actually not being prepared adequately to be a member of a clinical team. Is it just "we never had that communication skills malarkey in our day and we came out just fine"? M6
\end{abstract}

\section{DISCUSSION}

Clinician involvement in leadership and management has a beneficial effect on healthcare delivery and concomitantly the quality of patient care. ${ }^{8-10}$ If more of tomorrow's doctors are to engage in leadership and management there is a need to educate today's medical 
students. Despite the development of leadership and management education initiatives for first-year doctors, evidence of such developments at the undergraduate level are more limited. ${ }^{16}$

A recent systematic review identified leadership and management as one of the key competencies for undergraduate community-based education for health professionals. ${ }^{24}$ Our study suggests medical students may be more open and accepting of the role of leadership and management education in medical education than thought hitherto. Although we took as our starting points the MLCF it was not our intention to compare in detail the suggestions made by our students with suggestions for leadership and management education outlined in the guidance for undergraduate medical education. ${ }^{19}$ Nevertheless there are areas of commonality: encouraging students' appreciation of the perspectives of other stakeholders and of the organisational and societal context within which healthcare is delivered is one, as is the importance of making leadership and management education relevant in the clinical context. ${ }^{19}$ These results closely parallel findings from a study of medical education leaders, who cited 'attending to the world outside' as a key area of their work. ${ }^{25}$

Many viable topics were suggested including: structure of the NHS, facilitators of team working such as conflict resolution, negotiating and communication skills and decision-making. Patient safety was particularly important.

In common with other studies, experiential learning was preferred. ${ }^{26}$ Placements were seen to provide teaching opportunities. Structured observations, reflection on these, critical appraisal and analysis of mistakes at the individual and organisational level were all mentioned. Mindful of the crowded nature of the curriculum students identified opportunities for integrating leadership and management education.

Students' views about assessment were more diverse. Feedback figured prominently: in terms of how to give feedback, as a method for delivering leadership and management education and as a means of assessment. The importance of direct, timely and appropriate feedback in self-regulated learning has long been recognised. ${ }^{27}$

Some attitudes held by medical professionals and students and by society as a whole were seen as barriers to leadership and management education in the undergraduate medical curriculum. Changing attitudes is often slow and difficult.

\section{Strengths and weaknesses of the paper}

Using focus groups allowed for in-depth discussion and exploration of students' views. The size and number of the focus groups, together with the fact that participants were drawn from all 3 years of the clinical course meant a wide range of views were presented. The Management Leadership Competency Framework was derived from consensus discussions and its adoption as the basis for the focus group discussions lends support for the approach adopted. ${ }^{11}$

A significant weakness of the study is that it was based in one medical school with a significant 'preclinical/ clinical' curricular divide. As with most qualitative studies, participants were volunteers, potentially predisposed to leadership and management education. With the exception of the focus group discussion considering 'Setting Direction', it was not possible to provide participant validation of the results. Finally, although widely supported, the Management Leadership Competency Framework has been criticised for laying responsibility on the individual with little regard for the context and environment within which they operate. ${ }^{28}$

\section{Further work}

Studies in many sectors have highlighted generic obstacles to teaching leadership and management; those specifically applicable to the undergraduate medical curriculum include variability of leadership practices and lack of a consistent and deliberate practice in the field. ${ }^{29}$ Medical students witness a potentially confusing array of leadership styles and practices and without clear guidance they may be unable to evaluate what they observe. Whereas clinical skills can be practiced through simulation, providing such a practice field for leadership and management skills is more complex. This, together with the crowded nature of the curriculum, means that there are few opportunities for real-time coaching.

Further work might usefully explore the views of students earlier in their medical studies and the views of students engaged in different types of course design. However, there is a need to develop leadership and management education in some form at the present time. Perhaps, the most pragmatic approach would be to introduce small initial changes and modify them in the light of their evaluation.

\section{CONCLUSIONS}

These findings offer insights into how students view possible developments in leadership and management education. Although necessarily a partial view, it is relevant to the difficult choices that curriculum planners face seeking to strengthen education in this area in the face of an already overcrowded timetable. Perhaps, for them, students' insights into the opportunities to develop leadership and management learning within existing curricular experiences are most significant.

Author affiliations

${ }^{1}$ The Primary Care Unit, University of Cambridge, Cambridge, UK

${ }^{2}$ Queen Edith Medical Practice, Cambridge, UK

${ }^{3}$ Imperial College Healthcare NHS Trust, London, UK

${ }^{4}$ West Suffolk Hospital NHS Trust, Bury St Edmunds, UK

${ }^{5}$ Department of Medicine, Hinchingbrooke Health Care NHS Trust, Hinchingbrooke, Cambridgeshire, UK

${ }^{6}$ School of Clinical Medicine, University of Cambridge, Cambridge, UK ${ }^{7}$ General Practice Education Group, The Primary Care Unit, University of Cambridge, Cambridge, UK 
Contributors The study was conceived and designed jointly by MA, TQ, JB and DW. Focus group discussions were conducted by MA, TQ and SM. Data analysis was undertaken by TQ, SM, SH, FC and JB. TQ wrote the first draft of the paper with significant inputs from SH and FC. All authors were involved in refining this into the final draft.

Funding The research received no specific grant from any funding agency in the public, commercial or not-for-profit sectors.

Competing interests None.

Ethics approval The study received ethical approval from the University of Cambridge Psychology Ethics Committee (the relevant body for all studies involving University of Cambridge students).

Provenance and peer review Not commissioned; externally peer reviewed.

Data sharing statement Anonymised coded data from the study available from TQ.

Open Access This is an Open Access article distributed in accordance with the Creative Commons Attribution Non Commercial (CC BY-NC 4.0) license, which permits others to distribute, remix, adapt, build upon this work noncommercially, and license their derivative works on different terms, provided the original work is properly cited and the use is non-commercial. See: http:// creativecommons.org/licenses/by-nc/4.0/

\section{REFERENCES}

1. Darzi AV. Our NHS, our future: NHS next stage review. Interim Report. Department of Health, 2007.

2. Darzi AV. High quality care for all: NHS next stage review. Final Report. Department of Health, 2008.

3. Francis R. Report of the Mid Staffordshire NHS Foundation Trust Public Inquiry. The Stationary Office, 2013.

4. The King's Fund. Leadership and engagement for improvement in the NHS: together we can: the king's fund leadership review. The King's Fund, 2012.

5. Tooke J. Aspiring to excellence: final report of the independent inquiry into modernising medical careers. Medical Schools Council, 2008.

6. Goodall $\mathrm{AH}$. Physician-leaders and hospital performance: is there an association? Soc Sci Med 2011;73:535-9.

7. Lega F, Prenestini A, Spurgeon P. Is management essential to improving the performance and sustainability of health care systems and organizations? A systematic review and a roadmap for future studies. Value Health 2013;16(1 Suppl):S46-51.

8. Prybil LD. Size, composition, and culture of high-performing hospita boards. Am J Med Qual 2006;21:224-9.

9. Veronesi G, Kirkpatrick I, Vallascas F. Clinicians on the board: what difference does it make? Soc Sci Med 2013;77:147-55.
10. Dorgan S, Layton D, Bloom N, et al. Management in healthcare: why good practice really matters. London: McKinsey and Co. and LSE (CEP), 2010

11. Hewison A, Gale N, Yeats R, et al. An evaluation of staff engagement programmes in four National Health Service Acute Trusts. J Health Organ Manag 2013;27:85-105.

12. The King's Fund. The future of leadership and management in the NHS: no more heroes. London: The King's Fund, 2011.

13. NHS Institute for Innovation and Improvement and Academy of Medical Royal Colleges: Medical Leadership Competency Framework, Enhancing engagement in medical leadership. Second edition. Coventry. 2009.

14. NHS Institute for Innovation and Improvement. The clinical leadership competency framework. Coventry, 2011.

15. Royal College of Physicians. Learning to make a difference. http:// www.rcplondon.ac.uk/projects/learning-make-difference-ltmd

16. Bethune R, Soo E, Woodhead $\mathrm{P}$, et al. Engaging all doctors in continuous quality improvement: a structured, supported programme for first-year doctors across a training deanery in England. BMJ Qual Saf 2013;22:613-17.

17. Swanwick T, McKimm J. Clinical leadership requires system-wide interventions, not just courses. Clin Teach 2012;9:89-93.

18. General Medical Council. Tomorrow's doctors: Outcomes and standards for undergraduate medical education. General Medical Council, 2009.

19. Spurgeon P, Down I. Guidance for undergraduate medical education: integrating the medical leadership competency framework. NHS Institute for Innovation and Improvement and the Academy of Medical Royal Colleges, 2010

20. Dobson C, Cockson J, Allgar V, et al. Leadership training in the undergraduate medical curriculum. Educ Prim Care 2008;19:526-9.

21. Reid AM. Developing innovative leaders through undergraduate medical education. Educ Prim Care 2013;24:61-4.

22. Braun V, Clarke V. Using thematic analysis in psychology. Qual Res Psychol 2006;3:77-101.

23. Malterud K. Qualitative research: standards, challenges and guidelines. Lancet 2001;358:483-7.

24. Ladhani Z, Scherpbier AJ, Stevens FJ. Competencies for undergraduate community based education for the health professions: a systematic review. Med Teach 2012;39:733-43.

25. Lieff S, Albert M. What do we do? Practices and learning strategies of medical education leaders. Med Teach 2012:34:312-19.

26. Smith SE, Tallentire VR, Cameron HS, et al. The effect of contributing to patient care on medical students' workplace learning. Med Educ 2013;47:1184-96.

27. Nicol D, Macfarlane-Dick D. Formative assessment and self-regulated learning: a model and seven principles of good feedback practice. Stud High Educ 2006;31:199-218.

28. Bolden R, Gosling J. Leadership competencies: time to change the tune? Leadership 2006;2:147-63.

29. Allen SJ, Middlebrooks A. The challenge of educating leadership expertise. J Leadersh Stud 2013;6:84-9. 